\title{
VIRTUAL RESTORATION OF DAMAGED ARCHEOLOGICAL ARTIFACTS OBTAINED FROM EXPEDITIONS USING 3D VISUALIZATION
}

\author{
Dr. Subarna Shakya \\ Professor, Department of Electronics and Computer Engineering \\ Central Campus, Institute of Engineering, Pulchowk \\ Tribhuvan University, Pulchowk \\ Lalitpur Nepal - 44600 \\ Email: drss@,ioe.edu.np
}

\begin{abstract}
The paper puts forward the methodologies for the virtual restoration of the archeological artifacts that were obtained from the various missions. The proposed methodology combines the both the augmented and the virtual reality (C-ARVR) technologies enabling a virtual restoration of the artifacts that were damaged by visualizing the virtual three dimensional model with the actual one. The methodology provides an enhanced perception of the damaged substances. This enables the restoration of the historical artifacts that are more valuable.
\end{abstract}

Keywords: Virtual Recovery, Archeological Artifacts, 3D Visualization, digitalization, improved accuracy

\section{INTRODUCTION}

The virtual reality (VR) or the near reality is the arts and science of developing virtual environment to provide a protected, consistent and a flexible area for assessing different artifacts that are damaged[1-5], This achieved by exposing the user to the realistic multidimensional visual stimulus. The Virtual reality usually describes the three dimensional computer generated environment that could be easily interacted as well as reconnoitered by human beings.

It is an artificial environment that is developed using the software and offered to the user. The user who uses it considers and agrees it as the real environment, the virtual reality through the computer is basically known through the eye sight and the sound.

ISSN: 2582- 4252 
Journal of Innovative Image Processing (JIIP) (2019)

Vol.01/ No. 02

Pages: 102-110

https://www.irojournals.com/iroiip/

DOI: https://doi.org/10.36548/jiip.2019.2.005

The three dimensional images are most modest form of virtual reality that are exploited interactively by employing keys or the other devices in a PC. The objects in the image moves in a certain direction either in or out, classy efforts such as wrap around displays screens, actual rooms that are extended with the wearable computers and haptic devices helps us to feel the images[6-9].

This virtual reality is categorized as the simulation for a real environment to aid in education as well as training and the imagined environs for a game or interactive story. Some of the wide variety of applications virtual reality includes sports, architecture medicine, arts, entertainment etc[10-11].

The augmented reality (AR) combines the VR with the three dimensional real environs to achieve the integral images that augments the virtual scenarios with the real scenarios, the image integrated is overlapped on the real environment using the semitransparent glass. The figure.1 below pictures the virtual, augmented and the mixed reality.

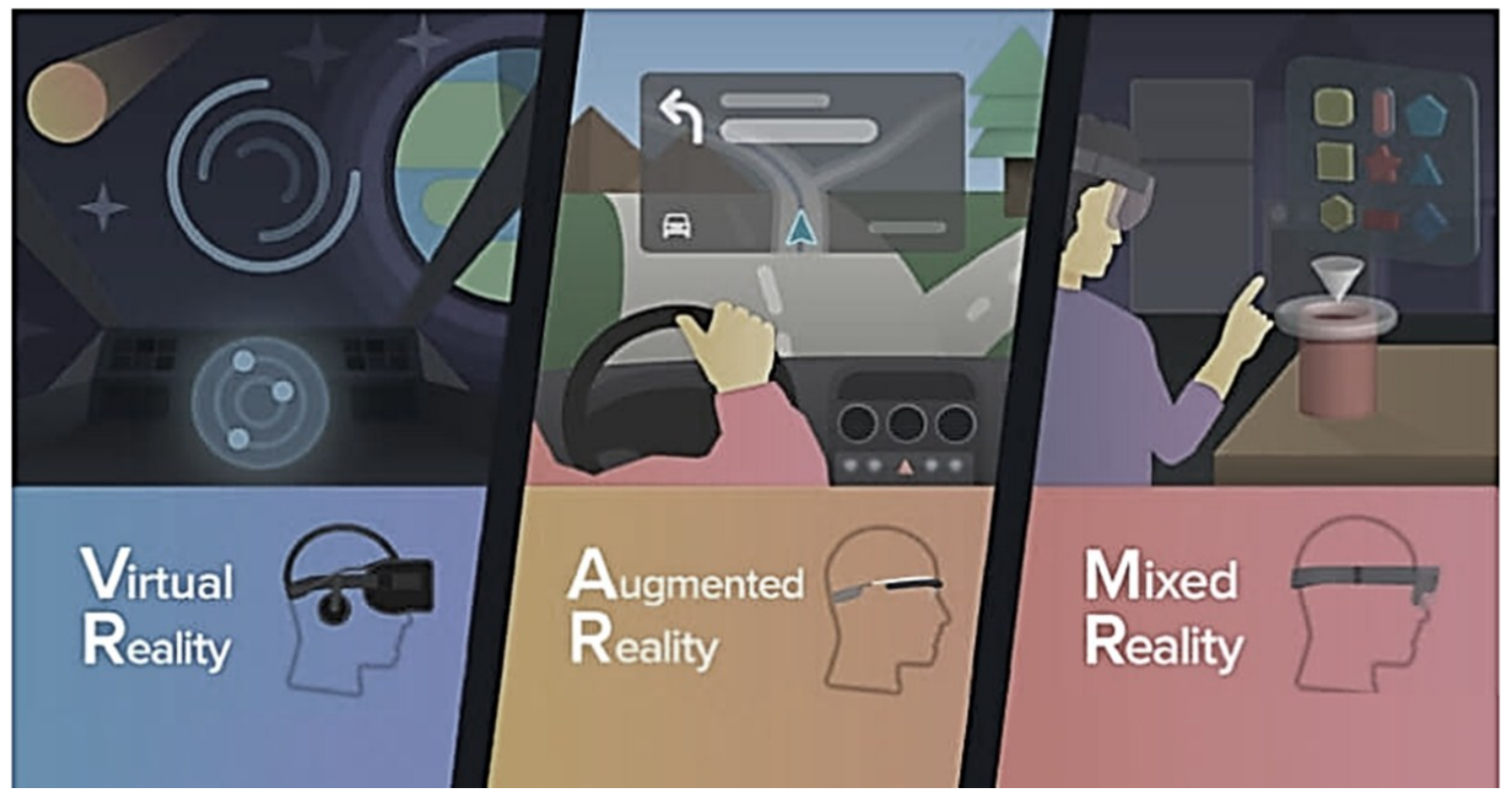

Figure.1 Virtual, Augmented and Mixed Reality

ISSN: 2582- 4252 
Journal of Innovative Image Processing (JIIP) (2019)

Vol.01/ No. 02

Pages: 102-110

https://www.irojournals.com/iroiip/

DOI: https://doi.org/10.36548/jiip.2019.2.005

In our proposed method the virtual reality and the augmented reality goes hand in hand to virtually restore the damaged artifacts that were identified through various expeditions. The figure .2 below provides the key difference between the virtual, augmented and mixed reality (MR).

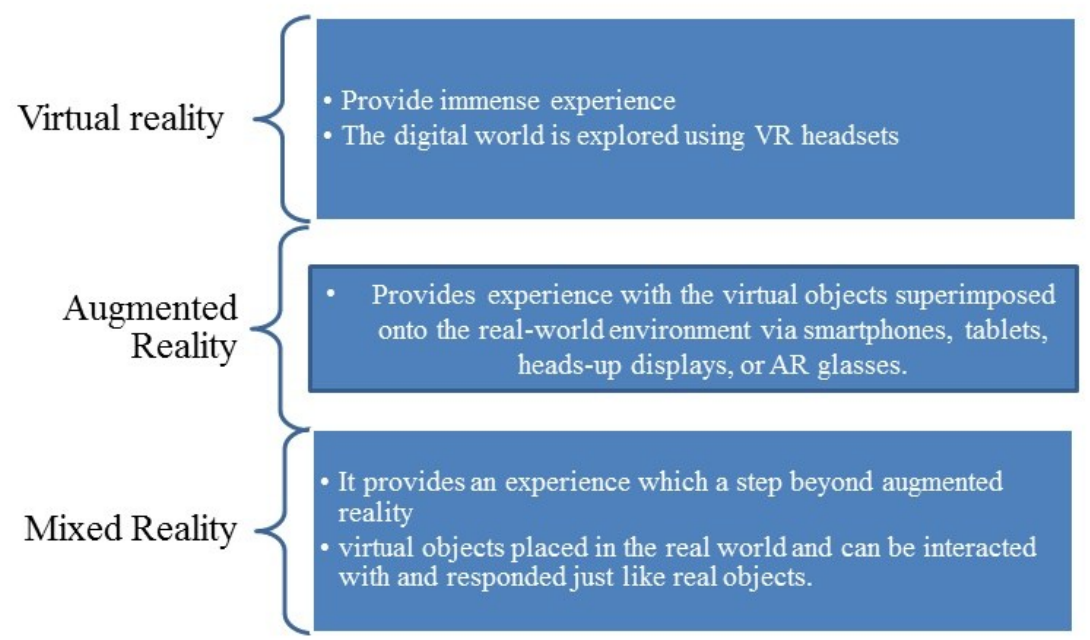

Figure .2 Key Differences of VR, AR and MR

The paper presents the existing work in the section 2, the proposed A-ARVR model in the section 3 and the performance improvements in the section 4 and the conclusion in the section 5 .

\section{EXISTING WORKS [12]}

The exiting method to renovate the damaged artifacts uses the subsequent fabrication method utilizing the 3-D scanning, CAD/CAM and 3-D Printing techniques to restructure the repaired design. The method utilizes the Artec Eva hand held scanner to acquire a multiple scans and combine them into a single and a fully completed three

ISSN: 2582- 4252 
Journal of Innovative Image Processing (JIIP) (2019)

Vol.01/ No. 02

Pages: 102-110

https://www.irojournals.com/iroiip/

DOI: https://doi.org/10.36548/jiip.2019.2.005

dimensional model. A mesh file is created in the STL format for the three dimensional images. The flow chart below in the figure. 3 shows the process involved in the existing method.

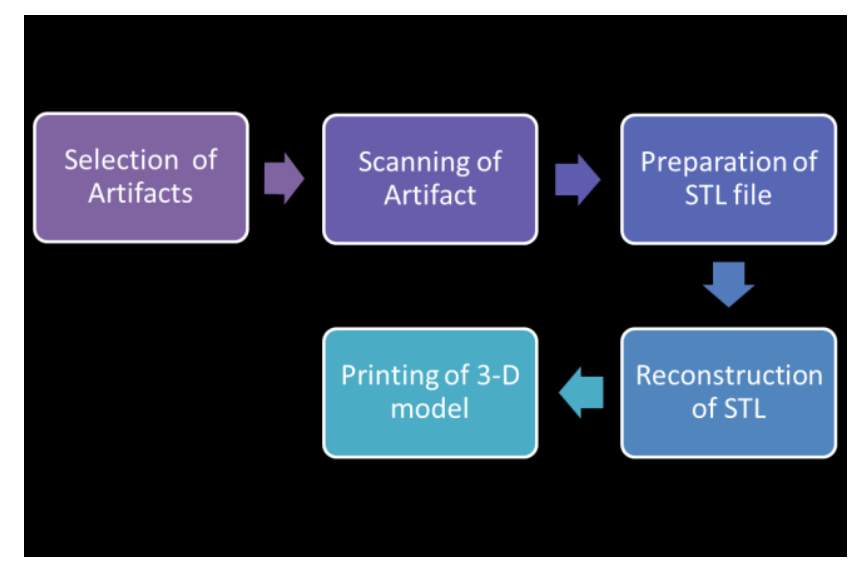

Figure.3 Existing Methods by Randhawa, Jagjit Singh,

The existing methodology included too many procedures to renovate the damaged artifacts making the process time consuming and costly.

\section{VIRTUAL RESTORATION OF THE DAMAGED ARTIFACTS UTILIZING THE C- ARVR}

The proposed method initially starts with the selection of the artifacts and utilizes the Ein scan Pro 3D scanners to scan to artifact and applies the C-ARVR to restructure and renovate the broken or the damaged artifacts and as well as recover the color of the objects, The block diagram below in figure. 4 shows the virtual restoration of the damaged true value archeological artifacts[13-14].

ISSN: 2582- 4252 
Journal of Innovative Image Processing (JIIP) (2019)

Vol.01/ No. 02

Pages: 102-110

https://www.irojournals.com/iroiip/

DOI: https://doi.org/10.36548/jiip.2019.2.005

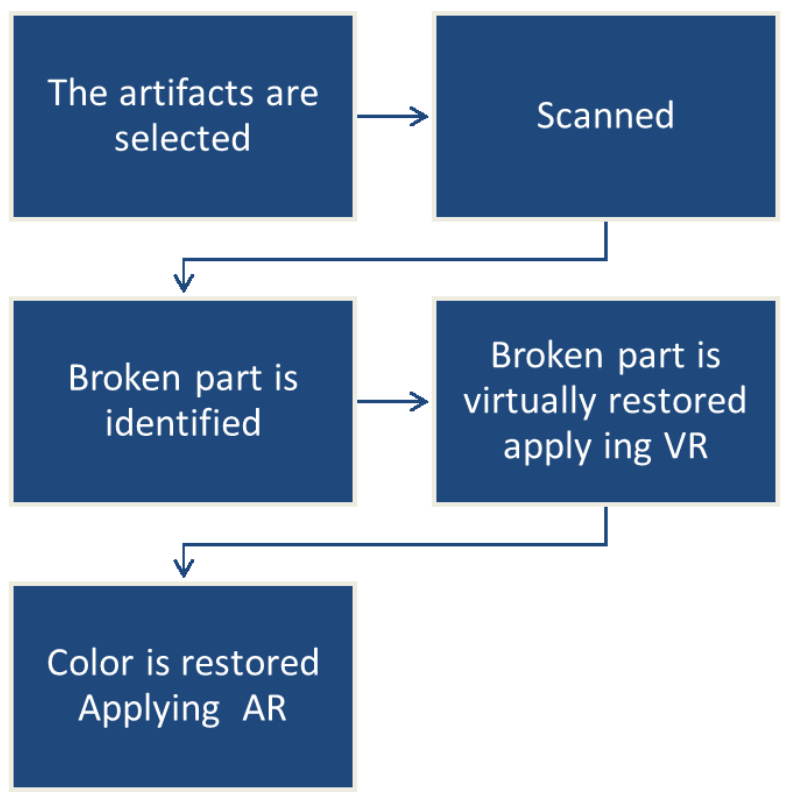

Figure.4 Block Diagram of Virtual Restoration

The steps below in the table .1 show the procedures in the restoration of the damaged artifacts that were obtained from the expeditions [15-19].

ISSN: 2582- 4252 


\begin{tabular}{|l|l|}
\hline Step 1: & $\begin{array}{l}\text { Selects artifacts that are not limited by the factors such as the color, size } \\
\text { transparency, lighting conditions and the available work space. }\end{array}$ \\
\hline Step 2: & $\begin{array}{l}\text { The selected artifact scanned using the Ein scan Pro 3D hand held } \\
\text { scanners, scans the artifacts simply without marking the reference points } \\
\text { on the surface of the artifacts. }\end{array}$ \\
\hline Step 3: & $\begin{array}{l}\text { The scanning is done within a } 10 \text { to } 15 \text { mins to capture the artifact, the } \\
\text { scanner movement needs to be minimal as the previous references has to } \\
\text { be preserved. }\end{array}$ \\
\hline Step 4: & $\begin{array}{l}\text { The computer generated virtual reality is uses the image based modelling } \\
\text { to pick up the } 3 \text { D images of the artifacts scanned }\end{array}$ \\
\hline Step 5: & $\begin{array}{l}\text { A revealing flashlight is used in the VR to develop the virtual copy of the } \\
\text { missing part with the information gained from the scanned images } \\
\text { obtained. }\end{array}$ \\
\hline Step 6: & $\begin{array}{l}\text { Later the AR Is applied to restore the color of the object by the controlled } \\
\text { spectrum lightening source } l_{i}(\lambda)=\frac{L i_{s}(\lambda)}{\widetilde{L} i_{s}(\lambda)} l(\lambda) \text { where the } l(\lambda) \text { is the } \\
\text { assumed perception } L i_{s}(\lambda) \text { and the } L i_{s}(\lambda) \text { are the original and the } \\
\text { discolored part }\end{array}$ \\
\hline Step 7: & $\begin{array}{l}\text { The Color correction pattern is projected as } \\
l_{i}(\lambda)=(1-k)(1-m i m(1, c)) R(\lambda)+(1-k)(1-m i m(1, m)) G(\lambda)+ \\
(1-k)(1-m i m(1, m)) B(\lambda) \text { where cmyk are color values of CMYK }\end{array}$ \\
\hline
\end{tabular}

Table .1 Steps in the Virtual Restoration

\section{PERFORMANCE ACHIEVED}

The table. 2 below provides the scanning factors of the artifacts that were obtained from the artifact gathered in an expedition. The figure. 5 provides the picture of the damaged ancient artifacts gathered from an ancient temple. 
Journal of Innovative Image Processing (JIIP) (2019)

Vol.01/ No. 02

Pages: 102-110

https://www.irojournals.com/iroiip/

DOI: https://doi.org/10.36548/jiip.2019.2.005

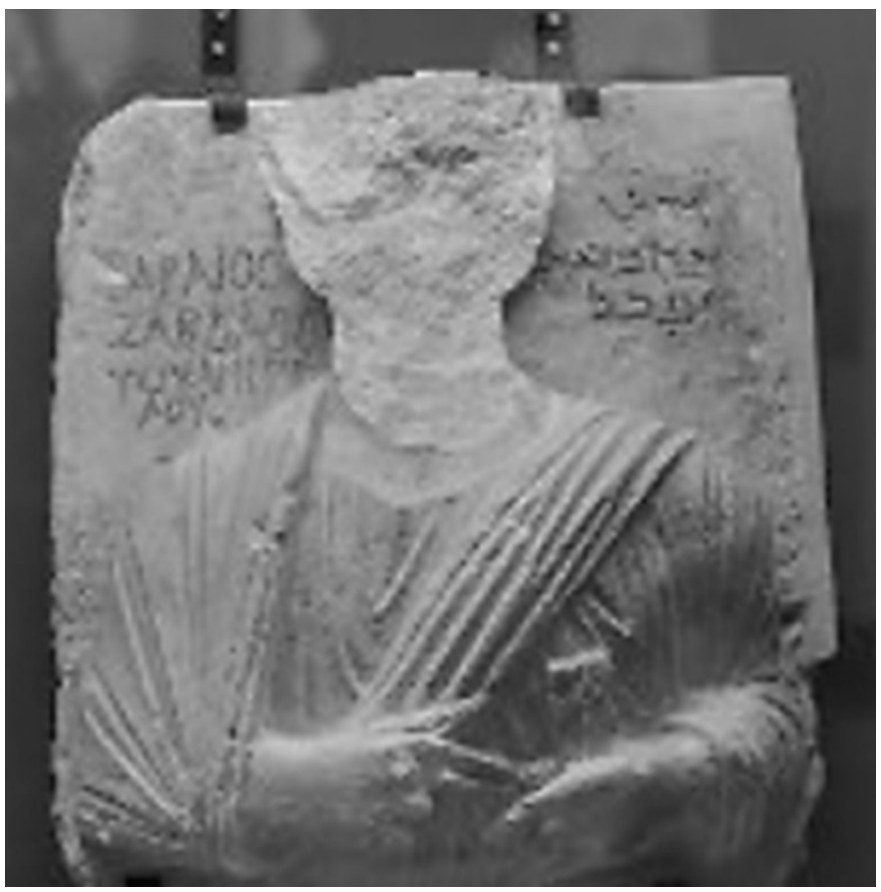

Figure. 5 Damaged Ancient Artifacts

\begin{tabular}{|c|c|c|c|}
\hline Scanned Face & length [CM] & Actual size [CM] & Difference \\
\hline Eyes & 23.2 & 18.1 & 5.1 \\
\hline Nose & 13.5 & 13 & .5 \\
\hline Ears & 10.7 & 9 & 1.7 \\
\hline Mouth & 12.7 & 12 & .7 \\
\hline Neck & 8.8 & 8.7 & .2 \\
\hline
\end{tabular}

Table.2 The Size of the Features Scanned 
Journal of Innovative Image Processing (JIIP) (2019)

Vol.01/ No. 02

Pages: 102-110

https://www.irojournals.com/iroiip/

DOI: https://doi.org/10.36548/jiip.2019.2.005

The figure. 6 below shows the reconstructed 3D image of the damaged artifact obtained in an expedition.

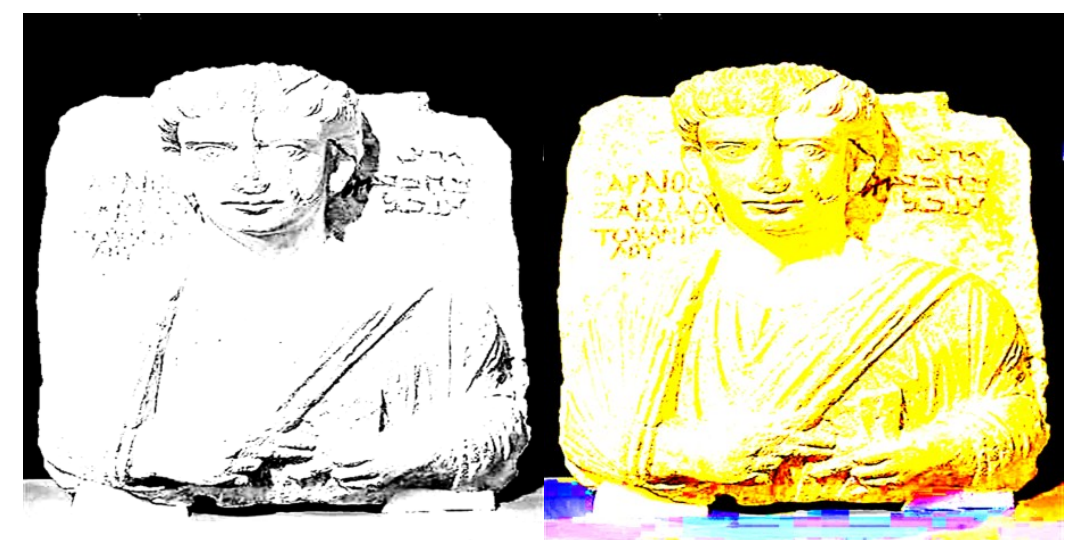

Figure.6 Reconstructed and Color Restored Artifact

The figure. 7 provides the accuracy of the in reconstruction compared to the prevailing methods.

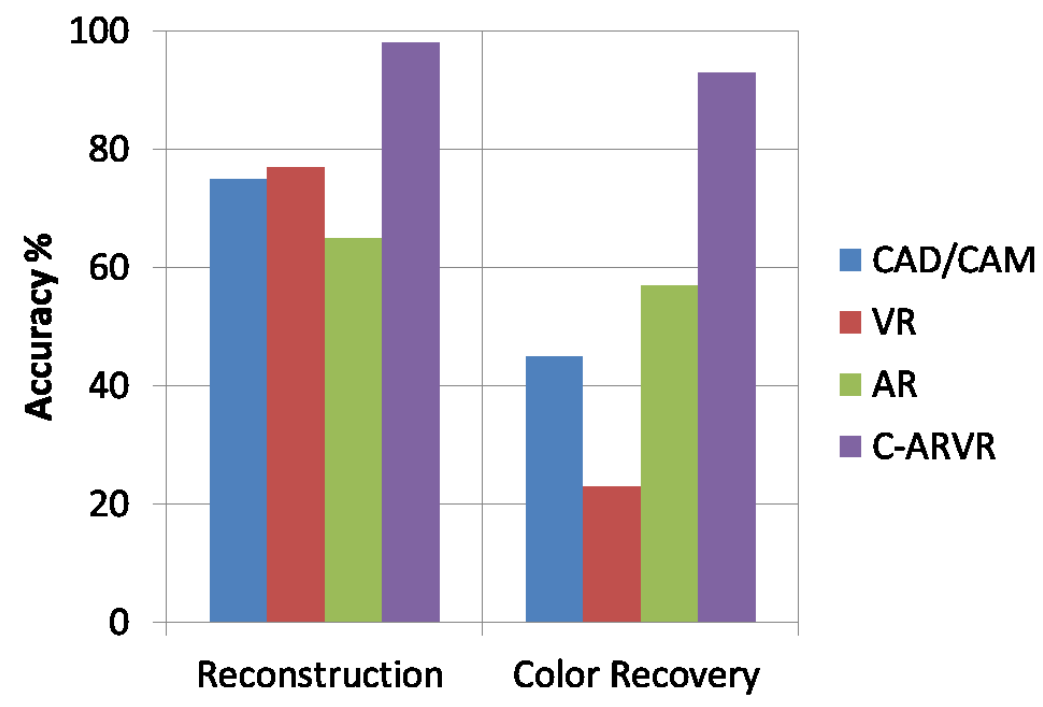

ISSN: 2582- 4252 
Journal of Innovative Image Processing (JIIP) (2019)

Vol.01/ No. 02

Pages: 102-110

https://www.irojournals.com/iroiip/

DOI: https://doi.org/10.36548/jiip.2019.2.005

Figure. 7 Accuracy in Restoration

\section{CONCLUSION}

The virtual reality and the augmented reality is used hand in hand to substantively change the way we interact with our digital technologies and to subsequently progressing in humanizing the technology. So the proposed method utilizes the C-ARVR in virtually restoring the damaged artifacts obtained from the ancient temple in Palmyra. The proposed method utilizes the VR to reconstruct the damaged artifact and the AR to restores the color of the artifact. Further the paper is to proceed in the future with the utilization of the C-ARVR in the facial surgery to recover the damaged skin in the face caused due to the uncertainties.

\section{References}

[1] Smys, S., and Jennifer S. Raj. "VIRTUAL REALITY SIMULATION AS THERAPY FOR POSTTRAUMATIC STRESS DISORDER (PTSD)." Journal of Electronics 1, no. 01 (2019): 24-34.

[2] Manoharan, Samuel. "AN IMPROVED SAFETY ALGORITHM FOR ARTIFICIAL INTELLIGENCE ENABLED PROCESSORS IN SELF DRIVING CARS." Journal of Artificial Intelligence 1, no. 02 (2019): 95-104.

[3] Bashar, Abul. "SURVEY ON EVOLVING DEEP LEARNING NEURAL NETWORK ARCHITECTURES." Journal of Artificial Intelligence 1, no. 02 (2019): 73-82.

[4] Koresh, Mr H. James Deva. "COMPUTER VISION BASED TRAFFIC SIGN SENSING FOR SMART TRANSPORT." Journal of Innovative Image Processing (JIIP) 1, no. 01 (2019): 11-19.

[5] Chandy, Abraham. "A REVIEW ON IOT BASED MEDICAL IMAGING TECHNOLOGY FOR HEALTHCARE APPLICATIONS." Journal of Innovative Image Processing (JIIP) 1, no. 01 (2019): $51-60$

[6] Smys, S. "VIRTUAL REALITY GAMING TECHNOLOGY FOR MENTAL STIMULATION AND THERAPY." Journal of Information Technology 1, no. 01 (2019): 19-26.

[7] Joby, P. P. "EXPLORING DEVOPS: CHALLENGES AND BENEFITS." Journal of Information Technology 1, no. 01 (2019): 27-37.

ISSN: 2582- 4252 
Journal of Innovative Image Processing (JIIP) (2019)

Vol.01/ No. 02

Pages: $102-110$

https://www.irojournals.com/iroiip/

DOI: https://doi.org/10.36548/jiip.2019.2.005

[8] Smys, S., and A. Dinesh Kumar. "Secured WBANs for pervasive m-healthcare social networks." In 2016 10th International Conference on Intelligent Systems and Control (ISCO), pp. 1-4. IEEE, 2016.

[9] Smys, S., Hui-Ming Wee, and Meng Joo. "Introduction to the Special Section on Inventive Systems and Smart Cities." (2018): 32-33.

[10] Smys, S., Jennifer S. Raj, and Nixon Augustine. "AUTONOUMOUS VEHICLE NAVIGATION IN COMMUNICATION CHALLENGED ENVIRONMENTS-A SIMULATION APPROACH." (2011).

[11] Kumar, N. Mohan. "ENERGY AND POWER EFFICIENT SYSTEM ON CHIP WITH NANOSHEET FET." Journal of Electronics 1, no. 01 (2019): 52-59.

[12] Randhawa, Jagjit Singh, and Akshat Gupta. "Virtual Restoration of Artefacts Using 3-D Scanning System."

[13] Sumner, T. Alexandra, and Andrew TR Riddle. "A virtual paleolithic: assays in photogrammetric three-dimensional artifact modelling." PaleoAnthropology 2008 (2008): 158-169.

[14] Garstki, Kevin. "Virtual representation: the production of 3D digital artifacts." Journal of Archaeological Method and Theory 24, no. 3 (2017): 726-750.

[15] Zheng, Jiang Yu, and Zhong Li Zhang. "Virtual recovery of excavated relics." IEEE Computer Graphics and Applications 19, no. 3 (1999): 6-11.

[16] Monteiro, Paula. "Computer Graphics in Archaeology."

[17] Kersten, T. P., and M. Lindstaedt. "Potential of automatic 3D object reconstruction from multiple images for applications in architecture, cultural heritage and archaeology." International Journal of Heritage in the Digital Era 1, no. 3 (2012): 399-420.

[18] Lu, Shi Zhu. "Virtual Reconstruction of FouGuang Temple Based on Virtual Reality." In 2008 International Conference on Management of e-Commerce and e-Government, pp. 208-211. IEEE, 2008.

[19] Amano, Toshiyuki, and Ryo Suzuki. "Virtual recovery of the deteriorated art object based on AR technology." In 2007 IEEE Conference on Computer Vision and Pattern Recognition, pp. 1-2. IEEE, 2007.

\footnotetext{
ISSN: 2582- 4252
} 